\title{
Relationships between attitudes and performance in young children's mathematics
}

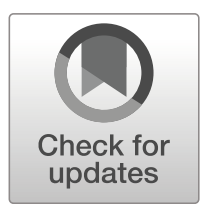

\author{
Ann Dowker ${ }^{1}$ (D) $\cdot$ Olivia Cheriton $^{2} \cdot$ Rachel Horton $^{3} \cdot$ Winifred Mark $^{4}$
}

Published online: 23 February 2019

(C) The Author(s) 2019

\begin{abstract}
Most studies of children's attitudes to mathematics have dealt with children in second grade or later, and have suggested that attitudes deteriorate, and anxiety increases with age. The present study investigated attitudes to mathematics in 67 English and 49 Chinese children at the end of their first year of school. The participants were given Thomas and Dowker's (2000) Mathematics Attitude Questionnaire, which uses pictorial rating scales to assess primary school children's mathematics anxiety, liking for mathematics, unhappiness at poor performance in mathematics, and self-rating in mathematics. They were also given the British Abilities Scales Basic Number Skills test. Attitudes were generally positive, though not more so than previously found for older primary school children. The Chinese children performed better in the arithmetic test and also rated themselves higher than the English children, but did not differ in other attitudes. Self-rating in mathematics and lack of unhappiness at poor performance were associated with better performance in the English group. There were no significant relationships between attitudes and performance in the Chinese group. Implications of the findings are discussed.
\end{abstract}

Keywords Young children - Attitudes to mathematics · Arithmetic · Mathematics anxiety Crosscultural $\cdot$ Chinese $\cdot$ English

\section{Introduction: theoretical and empirical background}

There has been much recent interest in attitudes to arithmetic, and especially in mathematics anxiety (Carey, Hill, Devine, \& Szucs, 2016; Dowker, Sarkar, \& Looi, 2016). This research

Ann Dowker

ann.dowker@psy.ox.ac.uk

Olivia Cheriton

olivia.cheriton@magdalen.oxon.org

Rachel Horton

Rachel.horton@st-annes.oxon.org

Winifred Mark

wmark@hku.hk 
has shown that mathematical ability is dependent not only on cognitive abilities such as IQ and working memory but also on emotional factors and attitudes toward mathematics. Thus, exploring the development of attitudes and emotions with respect to mathematics is an especially important area of research. In particular, it is important to study the relations between attitudes and performance, which attitudes are particularly important to performance, and when these relations may emerge.

Mathematics anxiety is the attitude that has received most attention in previous research. It has been defined as a feeling of tension and anxiety that interferes with the manipulation of numbers and the solving of mathematical problems (Richardson \& Suinn, 1972). It could be argued that this should not be classified as an attitude, as anxiety is predominantly emotional rather than evaluative. While acknowledging possible controversy on this issue, we here follow some previous researchers, such as Ma and Kishor (1997) in treating mathematics anxiety as an attitude. Many theories of attitudes incorporate affective components: e.g. Breckler's (1984) ABC model; and mathematics anxiety is thought to include both cognitive and affective components. Wigfield and Meece (1988) distinguish between a predominantly cognitive "worry" component, involving mathematics performance anxiety and a predominantly affective component, involving negative emotions in the presence of mathematical stimuli. The present paper deals predominantly with the cognitive "worry" component.

One reason why mathematics anxiety has received so much attention is because of its negative association with mathematical performance. Higher levels of mathematical anxiety have been linked to lower performance in high school tests, lower enjoyment of mathematics, and decreased motivation to take advanced mathematics courses (Hembree, 1990; Ma \& Kishor, 1997).

Several different explanations have been proposed for the relation between mathematics anxiety and mathematical performance. One explanation for the negative relation is that high mathematical anxiety leads to avoidance of mathematics-related activities, affording less opportunity for practice (Ashcraft, 2002). Another theory is that higher levels of mathematical anxiety lead to greater mental rumination and preoccupying thoughts, and that this consumes working memory resources (Eysenck, 1992).

The relation between mathematics anxiety and performance seems to be bidirectional. In addition to mathematics anxiety having a negative impact on mathematics performance, poor performance in mathematics is also likely to increase anxiety (Ganley \& Lubienski, 2016; Maloney \& Beilock, 2012; Maloney, Ansari, \& Fugelsang, 2011). Longitudinal studies provide evidence for both types of relation. For example, Ma and Xu (2004) found evidence of stronger correlations between performance and mathematical anxiety than between anxiety and performance across time. On the other hand, Cargnelutti, Tomasetto, and Passolunghi (2017), in a longitudinal study of progression from second to third grade, found a stronger predictive relation of mathematics anxiety to performance than the other way around. Thus, there is evidence that mathematical anxiety both influences and is influenced by performance. Jansen et al. (2013) argue that this leads to a vicious cycle where higher anxiety can lead to suboptimal strategy use or avoidance behaviour, which might then negatively impact performance and increase anxiety.

Most studies of attitudes to mathematics and mathematics anxiety have been done in secondary school children and adults. This leaves a significant gap in knowledge regarding when and how positive and negative feelings toward mathematics develop. Understanding this could potentially help to encourage the development of positive attitudes toward mathematics, and to prevent or reduce mathematics anxiety. Fortunately, in recent years, several scales have been developed to assess primary school children's attitudes to mathematics (Adelson \& 
McCoach, 2011; Dowker, Bennett, \& Smith, 2012; Ganley \& McGraw, 2016; Harari, Vukovic, \& Bailey, 2013; Jameson, 2013; Ramirez, Gunderson, Levine, \& Beilock, 2013; Wu, Barth, Amin, Malcarne, \& Menon, 2012).

On the whole, studies suggest that primary school children's attitudes to mathematics tend to be positive, but that they deteriorate with age during childhood and adolescence (Gierl \& Bisanz, 1995; Krinzinger, Kaufmann, \& Willmes, 2009; Ma \& Kishor, 1997; Wigfield \& Meece, 1988). However, some studies (e.g. Jameson, 2013, 2014) have elicited evidence of early-developing mathematics anxiety. In some studies, even first-graders have been shown to report and demonstrate mathematics anxiety (Jameson, 2014; Ma \& Kishor, 1997; Ramirez et al., 2013; Vukovic, Kieffer, Bailey, \& Harari, 2013). Petronzi (2016) reported significant mathematics anxiety in children as young as five. In contrast with the general findings showing deterioration in attitudes with age, Sorvo et al. (2017) found that Finnish children in Year 2 showed greater anxiety in Year 2 than children in later elementary grades.

Although mathematics anxiety dominates studies of attitudes of mathematics, other attitudes are also potentially important and are investigated in the present study. For example, there is evidence that experiences of failure and resulting discouragement are contributory factors to the development of mathematics anxiety (Maloney et al., 2011). Thus, it is important to study the extent to which children experience unhappiness in response to episodes of failure in, or inability to perform, a mathematical task. Though likely to be associated with mathematics anxiety, it is not identical with it, since it refers to unhappiness in response to failure rather than anxiety in anticipation of failure. For example, a child may generally anticipate success in mathematics, and not experience much anxiety, but be distressed on those occasions when they do experience failure. We wished to investigate whether mathematics anxiety and unhappiness at failure might have different associations with mathematical performance.

Most studies have focused on the more negative attitudes to mathematics, especially anxiety. However, positive attitudes such as enjoyment of mathematics and self-confidence in mathematics are also important topics to study, and cannot be reduced to the simple absence of anxiety.

Confidence in one's own mathematical ability is usually found to be positively related to performance (Abed \& Alkhateeb, 2000; Pinxten, Marsh, DeFraine, Van den Noortgate, \& Van Damme, 2014). Indeed, some studies suggest that in primary school children, mathematical performance may correlate more with self-rating than with anxiety (Dowker et al., 2012; Krinzinger et al., 2009; Wood et al., 2012) and that at all ages it may have a significant mediating role for the relations between mathematical performance and anxiety and other attitudes (Pinxten et al., 2014; Van der Beek, Van der Ven, Kroesbergen, \& Leseman, 2017). Most studies show a decline in self-rating with age (House, 2006; Upadyaya \& Eccles, 2015).

Enjoyment of mathematics is an important construct in itself, and also because it may influence the extent to which children are willing to practice mathematical activities, which may enable them to improve in the subject. Most studies indicate that younger children report high levels of enjoyment of mathematics, though there are some exceptions (Markovits \& Forgasz, 2017). However, the same studies mostly suggest that enjoyment deteriorates with age (Adelson \& McCoach, 2011; Blatchford, 1996; Gierl \& Bisanz, 1995; Gottfried, Marcoulides, Gottfried, Oliver, \& Guerin, 2007; House, 2006; Upadyaya \& Eccles, 2014; Wigfield \& Meece, 1988). Van der Beek et al. (2017) found that mathematics achievement correlated positively with mathematics enjoyment and negatively with mathematics anxiety in a Dutch adolescent sample. Pinxten et al. (2014) carried out a longitudinal study of Belgian upper primary school children, and mathematics enjoyment was a mild positive predictor of later mathematics achievement and later perceived effort in mathematics. There has been 
comparatively little research on the factors that cause children to like or dislike mathematics, but Upadyaya and Eccles (2014) found that teachers' ratings of primary pupils' effort and ability in mathematics predict not only their subsequent achievement and self-rating in mathematics, but their subsequent enjoyment of it.

The studies which have been done on relations between attitudes and performance in younger primary school children have shown mixed results as regards both the extent to which attitudes predict performance, and the attitudes that are the strongest predictors of performance. On the one hand, some studies do not show a relationship between mathematics anxiety and achievement (Dowker et al., 2012; Krinzinger et al., 2009). Dowker et al. (2012) obtained results which suggested that performance is related to self-rating rather than to mathematics anxiety, and that this relationship develops over time, and is not present in younger primary school children. On the other hand, studies by Wu et al. (2012) and Vukovic et al. (2013) found that mathematical anxiety correlated with performance even in the early years of elementary school.

The present study aimed to examine attitudes to mathematics and any relationships to performance in children at the end of Year 1 in primary school. It was expected that children of this age would show relatively positive attitudes, with high levels of liking for mathematics and self-rating for mathematics, and low anxiety. It was not predicted that there would be any relationship between attitudes and performance, as other studies using similar methodology have suggested that this only emerges somewhat later.

It also aimed to investigate whether there are gender differences in very young children's attitudes. Most studies suggest that adolescent and adult females are more anxious than males about mathematics, and have generally less positive attitudes to the subject (Devine, Fawcett, Szucs, \& Dowker, 2012; Else-Quest, Hyde, \& Linn, 2010; Hembree, 1990; Kyttala \& Bjorn, 2010), though in most recent studies they do not in fact perform worse than males. Some studies suggest that the relations between mathematics anxiety and performance may indeed differ between males and females, though findings have been conflicting, with some studies reporting a greater relationship between anxiety and performance in boys (Hembree, 1990; Ma $\& \mathrm{Xu}, 2004)$ and some in girls (Devine et al., 2012).

Gender differences in mathematics anxiety seem, however, to be mostly restricted to secondary school pupils and adults. In most studies, younger children do not show gender differences in mathematics anxiety (Dowker et al., 2012; Erturan \& Jansen, 2015; Harari et al., 2013; Wu, Willcutt, Escovar, \& Menon, 2014). This may, however, depend to some degree on how mathematics anxiety is defined and measured. Sorvo et al. (2017) found that Finnish primary school girls showed more negative emotional reactions to mathematics than boys, though they did not express greater anxiety about performance.

Studies of attitudes other than anxiety have shown gender differences in attitudes even at primary school level. By far the most consistent gender difference found regarding primary school children's attitudes has been found for self-rating. For example, Dowker et al. (2012) found that primary school boys rated themselves higher in mathematics than girls, despite showing no significant differences in other attitudes or in actual performance. Similarly, Ganley and Lubienski (2016) found that primary school children showed few gender differences in their liking for and interest in mathematics, but that boys were more confident. Herbert and Stipek (2005), Kyttala \& Bjorn (2010), Markovits \& Forgasz (2017), Skaalvik and Skaalvik (2004), and Upadyaya and Eccles (2015) also found that primary school boys showed more confidence than girls in their own mathematical ability. In the present study, it was predicted that, as in the study by Dowker et al. (2012), there would be no gender differences in either anxiety or in actual performance, but that boys would rate themselves higher. 
Finally, we wished to investigate possible cross-cultural differences in attitudes and in the relation between attitudes and performance. Specifically, we wished to compare first-grade children in England and Hong Kong, as this might elucidate some seemingly conflicting findings about within- and between-country associations between mathematics attitudes and performance. International comparisons consistently show better mathematics performance by Chinese children, and those in other Pacific Rim countries, than in most other countries. One might therefore expect that Chinese children would have more positive attitudes to mathematics than those in most other countries. Within Chinese samples, there is indeed a significant negative relationship between mathematics anxiety and performance, as in virtually all other countries (Dulaney, Herts, Borgonovi, \& Beilock, 2017). House (2006) found similar results with regard to another Pacific Rim country with regard to other attitudes. Although Japanese 9year-olds performed much better in mathematics than American 9-year-olds, both groups showed positive relationships between mathematical performance and both enjoyment of mathematics and finding it "easy".

However, several studies have indicated that, in contrast to children from high-performing West European countries, children from China and other East Asian countries show greater mathematics anxiety and less confidence and enjoyment than those in most lower-attaining countries, including England (Dulaney et al., 2017; Mullis, Martin, \& Loveless, 2016a). The TIMSS international comparisons have shown that Hong Kong pupils, and those elsewhere in the Pacific Rim, report less enjoyment and confidence in mathematics than those in most other countries, including England, both at younger (4th grade) and older (8th grade) ages.

This seems at first sight to be paradoxical. If negative attitudes are associated with poor performance in mathematics, why would pupils in high attaining countries show relatively negative attitudes? Possible explanations include the likelihood that they are comparing themselves with other high achieving peers rather than with the world in general; possible cultural pressures toward modesty (though this could only explain reduced confidence and not reduced enjoyment); and/or a high-pressure training regime which results both in high achievement and high anxiety. The question arises as to when the relatively negative attitudes begin. It is known that Chinese children already perform better on numerical tasks than Western children even at the time when they start school, but there is even less knowledge about very young Chinese children's attitudes to mathematics than about very young Western children's attitudes to mathematics.

Similarly, Ching (2017) found that Chinese children's mathematics anxiety negatively predicted their mathematics performance longitudinally from second to third grade, but only in the case of children who had relatively high working memory scores, suggesting that the effect of mathematics anxiety is most noticeable in children who do not have additional cognitive explanations for reduced attainment. This finding is not specific to Chinese children, but is similar to Ramirez et al.'s (2013) findings with American children. It has also been found that, as with children in other countries, Chinese children's attitudes to mathematics are closely linked to their parents' and teachers' attitudes (Stevenson et al. 2000). There has, however, been little research on the attitudes of Chinese children below second grade.

Our predictions were that (1) children in this age-range would have positive attitudes to mathematics; (2) that most attitudes would not correlate with arithmetical performance; (3) that self-rating would correlate with arithmetical performance in the Chinese and possibly in the English group; (4) that the Chinese children might already begin to show a negative withingroup correlation between mathematics anxiety and mathematics performance; (5) that Chinese children would perform better than English children at arithmetic; (6) that Chinese 
children would show greater mathematics anxiety than English children; (7) that English children would show higher self-rating than Chinese children; (8) that English children would express more liking for mathematics than Chinese children; (9) that there would be no gender difference in arithmetical performance; and (10) that boys would rate themselves higher in mathematics than girls.

\section{Methods}

\subsection{Participants}

Sixty-seven English participants were recruited from two non-fee-paying neighbourhood primary schools one in Carlisle, Cumbria, and one in Oxford. Forty-nine Chinese participants were recruited from two primary schools in Hong Kong. These were the same children whose performance on various numerical tasks was described by Mark and Dowker (2015). All children were tested in their native language.

The English children included 40 boys and 27 girls. Their mean age was 6 years 3 months (standard deviation 7.2 months). Unfortunately, due to confidentiality rules in the Hong Kong schools, we were not able to obtain detailed information as to the gender and exact ages of individuals. However, it is known that the mean age of the group was 6 years 10 months. None of the children in the study had known disabilities or special educational needs. Consent was obtained from the schools, and individual informed consent was obtained from the parents of all participants. The study received ethical approval from Oxford University's Central University Research Ethics Committee.

\subsection{Materials and procedure}

The participants completed two different assessments: a mathematics attitude questionnaire and an arithmetic calculation test.

\subsubsection{Mathematics attitude questionnaire}

Attitudes to mathematics were assessed using Thomas and Dowker's (2000) 28-item questionnaire (also see Dowker et al., 2012; Krinzinger et al., 2007). The questionnaire contains four scales, each including attitudes to seven aspects of mathematics: mathematics in general, written sums, mental sums, easy mathematics, difficult mathematics, mathematics tests, and understanding of the teacher talking about mathematics. For each item, children were asked about their Self-rating (how good they thought they were at it), Liking (how much they liked it), Anxiety (how anxious they would feel if they could not do it), and Unhappiness (how unhappy they would feel if they were unable to do it). The possible rating scores for each item ranged from 1 to 5 , where 1 was the most negative score and 5 was the most positive score. As there were seven items on each rating scale, the possible score on each rating scale ranged from 7 to 35 . For all scales, the scores were computed so that the more positive attitudes gave the higher score; so higher scores on the Anxiety and Unhappiness measures reflected low anxiety and low unhappiness. These measures are therefore termed in this article (Non)-Anxiety and (Non)-Unhappiness to clarify their direction.

For each set of items, the children were given four different five-point pictorial rating scales and asked to point to the picture that most represented their answers. Before starting the 
questionnaire, the children were given two sets of practice questions, on topics unrelated to mathematics, to familiarize them with the format of the rating scales. Self-rating was measured using "crosses and ticks" ( 2 crosses (very bad), 1 cross, blank space, 1 tick or 2 ticks (very good)). Liking was measured using "sweets and wasps" (2 wasps (hate very much), 1 wasp, blank space, 1 sweet, or 2 sweets (like very much)). Anxiety was measured using a Mr. Men scale (Mr Worry (very worried) to Mr. Happy (very relaxed)). Unhappiness at failure was measured with "emotive faces" (very frowny (very unhappy), frowny, flat mouthed face, smiley, or very smiley (very happy)). These scales were controlled for lateral preference by alternating the order.

In a study of 450 German children in their first 3 years of primary school, Krinzinger et al. (2007) had found that scale had good internal validity, with Cronbach's alpha for the four scales ranging from 0.83 to 0.91 , as well as good concurrent validity shown by high correlations with the TEDU-Math test.

\subsubsection{Arithmetical calculation test}

The children also completed a standardized arithmetic test: the Basic Number Skills subset of the British Ability Scales (BAS), 2nd edition (Blatchford, 1996). This edition of the British Ability Scales was standardized with 1659 children in the UK. The Basic Number Skills subtest is a test for pupils of 6 to 16, consisting of written arithmetic problems. There are 48 items in all, divided into six blocks of increasing difficulty The test is discontinued after a child gets fewer than 5 items correct within a block of 8 . The measure used in the analyses was Raw Score rather than Standard (scaled) Score, because the test was not standardized in Hong Kong, making Raw Score a more appropriate measure, and because the inability to obtain exact ages from individual Hong Kong pupils would have made it impossible to obtain standard scores.

\subsection{Procedure}

Each child was tested individually by a researcher in a quiet area near to their classroom. The children were informed that the purpose of the study was to find out what they thought about mathematics, and that they would be given a couple of tests. Verbal consent was then obtained from the child before continuing. None of the children refused to take part in any of the tasks.

\section{Results}

Table 1 shows the scores obtained by the English and Chinese groups on the British Abilities Scales Basic Number Skills test (raw score), and on the four attitude measures. Basic Number Skills test standard scores were only available for the English children, who obtained a mean standard score of 117.3 (s.d. 13.43). The lack of precise age information for individual Chinese children made it impossible to calculate individual standard scores for that group, but the mean age of 6 years 10 months combined with a mean raw score of 17.47 leads to an estimated mean standard score of approximately 130.

\subsection{Reliability of attitude measures}

Due to the relatively small samples, and the fact that the attitude questionnaire had not previously been used with Chinese children, it was important to check the reliability of the 
Table 1 Means and standard deviations of scores on arithmetic and attitude measures in English and Chinese children and results of independent sample $t$ tests comparing nationalities (standard deviation in brackets)

\begin{tabular}{|c|c|c|c|c|c|c|c|}
\hline & English & Chinese & Total & $\begin{array}{l}\text { Degrees of } \\
\text { freedom }\end{array}$ & $t$ & $p$ & Hedges' g \\
\hline $\mathrm{N}$ & 67 & 49 & 116 & - & - & - & - \\
\hline $\begin{array}{l}\text { BAS Basic Number } \\
\text { Skills Raw Score }\end{array}$ & $10.76(3.61)$ & $17.47(4.71)$ & $\begin{array}{l}13.59 \\
(5.28)\end{array}$ & 114 & 8.68 & $<0.001$ & 1.62 \\
\hline Liking for Mathematics & $26.52(6.67)$ & $28.22(5.49)$ & $\begin{array}{l}27.24 \\
(6.23)\end{array}$ & 114 & -1.46 & 0.15 & 0.27 \\
\hline Self-Rating & $\begin{array}{l}21.09 \\
(4.91)\end{array}$ & $\begin{array}{l}27.65 \\
(5.36)\end{array}$ & $23.86(6.04)$ & 114 & -6.83 & $<0.001$ & 1.27 \\
\hline (Non)-Anxiety & $18.69(7.21)$ & $20.08(6.76)$ & $19.27(7.03)$ & 114 & 0.784 & 0.43 & 0.2 \\
\hline $\begin{array}{l}\text { (Non)-Unhappiness } \\
\text { at Failure }\end{array}$ & $21.18(9.16)$ & $19.98(6.47)$ & $20.67(8.12)$ & 114 & -0.801 & 0.43 & 0.13 \\
\hline
\end{tabular}

attitude measures. These were satisfactory in both groups. In the English group, Cronbach's alpha was 0.75 for Self-Rating; 0.82 for Liking for Mathematics; 0.85 for Anxiety; and 0.9 for Unhappiness at Failure. In the Chinese group, Cronbach's alpha was 0.83 for Self-Rating; 0.75 for Liking for Mathematics; 0.84 for Anxiety; and 0.85 for Unhappiness at Failure.

Table 2 shows the correlations between all the scores in the group as a whole.

As Table 2 shows, the only significant correlate of Basic Number Skills in the group as a whole was Self-Rating. Significant correlations between the attitudes include correlations between Liking for Mathematics and Self-Rating; Liking for Mathematics; and (Non)-Unhappiness at Failure; and Self-Rating and (Non)-Anxiety.

Table 3 indicates that in the English group on its own, the only significant correlate of Basic Number Skills was (Non)-Unhappiness at Failure, though the correlation with Self-Rating almost reached significance (Table 3). Significant correlations between the attitudes include correlations between Liking for Mathematics and (Non)-Unhappiness at Failure; and (Non)Anxiety and (Non)-Unhappiness at Failure.

Table 4 indicates that the only significant correlate of Basic Number Skills in the Chinese group was Self-Rating. Self-rating correlated significantly with all the other attitude variables: Liking for Mathematics; (Non)-Anxiety and (Non)-Unhappiness at Failure. (Non)-Anxiety correlated with (Non)-Unhappiness at Failure (Table 4).

\subsection{Multiple regressions}

An entry-type linear multiple regression was carried out for the whole group with British Abilities Basic Number Skills Raw Score as the dependent variable and Liking for

Table 2 Correlations between arithmetic score and attitude scores in the group as a whole

\begin{tabular}{|c|c|c|c|c|c|}
\hline & $\begin{array}{l}\text { BAS Basic Number } \\
\text { Skills Raw Score }\end{array}$ & $\begin{array}{l}\text { Liking for } \\
\text { Mathematics }\end{array}$ & Self-Rating & $\begin{array}{l}\text { (Non)- } \\
\text { Anxiety }\end{array}$ & $\begin{array}{l}\text { (Non)-Unhappiness } \\
\text { at Failure }\end{array}$ \\
\hline $\begin{array}{l}\text { BAS Basic Number } \\
\text { Skills Raw Score }\end{array}$ & & 0.196 & $0.51 * *$ & 0.036 & 0.139 \\
\hline Liking for Mathematics & & & $0.347 * *$ & 0.053 & $0.297 * *$ \\
\hline Self-Rating & & & & $0.193 *$ & 0.008 \\
\hline (Non)-Anxiety & & & & & -0.06 \\
\hline
\end{tabular}

$* p<0.05 ; * * p<0.01$ 
Table 3 Correlations between arithmetic score and attitude scores in the English group only

\begin{tabular}{|c|c|c|c|c|c|}
\hline & $\begin{array}{l}\text { BAS Basic Number } \\
\text { Skills Raw Score }\end{array}$ & $\begin{array}{l}\text { Liking for } \\
\text { Mathematics }\end{array}$ & $\begin{array}{l}\text { Self- } \\
\text { Rating }\end{array}$ & $\begin{array}{l}\text { (Non)- } \\
\text { Anxiety }\end{array}$ & $\begin{array}{l}\text { (Non)- } \\
\text { Unhappiness at } \\
\text { Failure }\end{array}$ \\
\hline $\begin{array}{l}\text { BAS Basic Number } \\
\text { Skills Raw Score }\end{array}$ & & 0.185 & $0.237(*)$ & 0.067 & $0.342 * *$ \\
\hline Liking for Mathematics & & & 0.062 & 0.106 & $0.336^{* *}$ \\
\hline Self-Rating & & & & 0.133 & -0.192 \\
\hline (Non)-Anxiety & & & & & $0.409 * *$ \\
\hline
\end{tabular}

$(*) p=0.06 ; * p<0.05 ; * * p<0.01$

Mathematics, Self-Rating, (Non)-Anxiety, and (Non)-Unhappiness at Failure as the predictors. The regression overall was significant $(\mathrm{F}(4,112)=10.983 ; p<0.001) . \mathrm{R}^{2}=0.284 ; \mathrm{R}^{2}$ adjusted $=0.248$ ). The predictor variables explained $24.8 \%$ of the variance in Basic Number Skills Raw Score. The regression table is shown in Table 6.

As Table 5 shows, the only significant independent predictor of Basic Number Skills Raw Score in the whole group was Self-Rating, though (Non)-Unhappiness at Failure approached significance.

A similar regression analysis was carried out for the English children only. The regression overall was significant $\left(\mathrm{F}(4,63)=4.014, p=0.006 ; \mathrm{R}^{2}=0.206 ; \mathrm{R}^{2}\right.$ adjusted $\left.=0.154\right)$. The regression table is shown in Table 6.

Table 6 indicates that the only significant predictors of Basic Number Skills Raw Score in the English group were Self-Rating and Unhappiness at Failure.

A similar regression analysis was carried out for the Chinese children only. The regression was non-significant overall $\left(\mathrm{F}(4,45)=1.244 ; p=0.306 ; \mathrm{R}^{2}=0.102 ; \mathrm{R}^{2}=0.02\right)$. The regression table is shown in Table 8.

Not surprisingly, Table 7 indicates that no predictor was independently significant in the Chinese group, though there was a trend for Self-Rating to predict Raw Score.

\subsection{Collinearity checks}

Multicollinearity was checked for all the attitude measures included in the multiple regression on Raw Score, within each nationality group and within the whole group. It was found not to be at a problematic level for any measure. The Variance Inflation Factor ranged from 1.01 (Self-rating) to 1.502 (Unhappiness at Failure) within the English group and from 1.75 (Liking for Mathematics) to 2.27 (Anxiety) within the Chinese group. Within the group as a whole, the

Table 4 Correlations between arithmetic score and attitude scores in the Chinese group only

\begin{tabular}{|c|c|c|c|c|c|}
\hline & $\begin{array}{l}\text { BAS Basic Number } \\
\text { Skills Raw Score }\end{array}$ & $\begin{array}{l}\text { Liking for } \\
\text { Mathematics }\end{array}$ & $\begin{array}{l}\text { Self- } \\
\text { Rating }\end{array}$ & $\begin{array}{l}\text { (Non)- } \\
\text { Anxiety }\end{array}$ & $\begin{array}{l}\text { (Non)- } \\
\text { Unhappiness at } \\
\text { Failure }\end{array}$ \\
\hline $\begin{array}{l}\text { BAS Basic Number } \\
\text { Skills Raw Score }\end{array}$ & & 0.099 & $0.283^{* *}$ & 0.156 & 0.112 \\
\hline Liking for Mathematics & & & $0.674 * *$ & 0.27 & 0.254 \\
\hline Self-Rating & & & & $0.345 *$ & $0.325^{*}$ \\
\hline (Non)-Anxiety & & & & & $0.739 * *$ \\
\hline
\end{tabular}

$* p<0.05 ; * * p<0.01$ 
Table 5 Regression table for attitude variables on raw score in the whole group

\begin{tabular}{|c|c|c|c|c|c|c|}
\hline \multirow{2}{*}{\multicolumn{2}{|c|}{ Model }} & \multicolumn{2}{|c|}{ Unstandardized coefficients } & \multirow{2}{*}{$\begin{array}{l}\text { Standardized coefficients } \\
\text { Beta }\end{array}$} & \multirow[t]{2}{*}{$t$} & \multirow[t]{2}{*}{ Sig. } \\
\hline & & $\mathrm{B}$ & Std. error & & & \\
\hline \multirow[t]{5}{*}{1} & (Constant) & 2.036 & 2.377 & & 0.856 & 0.394 \\
\hline & Self-Rating & 0.476 & 0.080 & 0.544 & 5.962 & 0.000 \\
\hline & Liking & -0.039 & 0.079 & -0.046 & -0.496 & 0.621 \\
\hline & Anxiety & -0.066 & 0.075 & -0.087 & -0.884 & 0.379 \\
\hline & Unhappiness & 0.124 & 0.066 & 0.191 & 1.890 & 0.061 \\
\hline
\end{tabular}

Dependent variable: Raw Score

Variance Inflation Factor ranged from 1.29 (Self-Rating) to 1.58 (Unhappiness at Failure). Since even the most conservative criteria treat a Variance Inflation Factor of less than 2.5 as unlikely to be problematic, we may assume that multicollinearity was not a major issue in the present study,

\subsection{Gender differences (English group only)}

Gender information about individuals was only available for the English group (Table 8).

Analyses of variance were carried out with Gender (Male versus Female) as the grouping factor, and British Abilities Scales Basic Number Skills raw score and all the attitude scores as the dependent variables. As can be seen, there were no significant gender differences in arithmetic score, Liking for mathematics, or Self-rating; but girls showed significantly less Anxiety about mathematics or Unhappiness at failure than did boys.

Individual exact age information was also only available for the English group. Within that group, Pearson correlation coefficients were computed between Age in months, and the Arithmetic and Attitude scores. No correlation between any score and Age was significant.

\section{Discussion}

The results indicate that in the English group attitudes to mathematics did show significant relationships to arithmetical performance, even at this early age. In particular, both self-rating and (non)-unhappiness at failure was associated with performance. In the Chinese group, there was a correlation between self-rating and performance, but it ceased to reach significance after

Table 6 Regression table for attitude variables on raw score in the English group

\begin{tabular}{|c|c|c|c|c|c|c|}
\hline \multicolumn{2}{|c|}{ Model } & \multicolumn{2}{|c|}{ Unstandardized coefficients } & \multirow{2}{*}{$\begin{array}{l}\text { Standardized coefficients } \\
\text { Beta }\end{array}$} & \multirow[t]{2}{*}{$t$} & \multirow[t]{2}{*}{ Sig. } \\
\hline & & B & Std. error & & & \\
\hline \multirow[t]{5}{*}{1} & (Constant) & 4.037 & 2.537 & & 1.591 & 0.117 \\
\hline & Self-Rating & 0.218 & 0.087 & 0.296 & 2.501 & 0.015 \\
\hline & Liking & -0.003 & 0.069 & -0.005 & -0.037 & 0.970 \\
\hline & Anxiety & -0.071 & 0.067 & -0.141 & -1.070 & 0.289 \\
\hline & Unhappiness & 0.168 & 0.055 & 0.426 & 3.071 & 0.003 \\
\hline
\end{tabular}

Dependent variable: Raw Score 
Table 7 Regression table for attitude variables on raw score in the Chinese group

\begin{tabular}{|c|c|c|c|c|c|c|}
\hline \multicolumn{2}{|c|}{ Model } & \multicolumn{2}{|c|}{ Unstandardized coefficients } & \multirow{2}{*}{$\begin{array}{l}\text { Standardized coefficients } \\
\text { Beta }\end{array}$} & \multirow[t]{2}{*}{$t$} & \multirow[t]{2}{*}{ Sig. } \\
\hline & & B & Std. error & & & \\
\hline \multirow[t]{5}{*}{1} & (Constant) & 11.646 & 3.962 & & 2.939 & 0.005 \\
\hline & Self-Rating & 0.332 & 0.175 & 0.378 & 1.898 & 0.064 \\
\hline & Liking & -0.149 & 0.166 & -0.173 & -0.894 & 0.376 \\
\hline & Anxiety & 0.074 & 0.150 & 0.105 & 0.490 & 0.626 \\
\hline & Unhappiness & -0.032 & 0.155 & -0.045 & -0.209 & 0.836 \\
\hline
\end{tabular}

Dependent variable: Raw Score

controlling for other attitudes. The Chinese children performed better in arithmetic than the English children, and also gave themselves higher self-ratings. They did not differ in other attitudes.

These results will now be discussed in greater detail. We will first discuss the attitudes themselves, and then the relationship between attitudes and performance. We will then discuss similarities and differences between the English and Chinese children. We will then discuss relationships between the different attitudes. The discussion will then turn to gender differences within the English group, where boys and girls performed equally well but girls seemed to have lower mathematics anxiety. Finally, we will discuss some limitations of the study, and implications for further research and for education.

\subsection{Relatively positive attitudes to mathematics}

As predicted by the first hypothesis, the children in this study demonstrated relatively positive attitudes to mathematics, with a mean score for Liking for Mathematics of 27.25 out of 35, and also fairly high scores for Self-rating and on Freedom from Anxiety and Unhappiness at Failure. This is consistent with other findings that show that, though primary school children are not immune to negative attitudes about mathematics (Petronzi, 2016), most express positive attitudes to it (Blatchford, 1996; Dowker et al., 2012; Gierl \& Bisanz, 1995; Upadyaya \& Eccles, 2014; Wigfield \& Meece, 1988). Most of these previous studies had not looked at children as early as the

Table 8 Scores on arithmetic and attitude measures in English boys and girls and results of ANOVAs comparing genders

\begin{tabular}{|c|c|c|c|c|c|c|c|}
\hline & Boys & Girls & Total & $\begin{array}{l}\text { Degrees of } \\
\text { freedom }\end{array}$ & $t$ & $p$ & Hedges' $g$ \\
\hline$N$ & 40 & 27 & 67 & - & - & - & - \\
\hline $\begin{array}{l}\text { BAS Basic Number } \\
\text { Skills Raw Score }\end{array}$ & $\begin{array}{l}10.48 \\
(3.36)\end{array}$ & $\begin{array}{l}11.09 \\
(3.72)\end{array}$ & $\begin{array}{l}10.76 \\
(3.61)\end{array}$ & 1,66 & $0 . .65$ & 0.518 & 0.1 \\
\hline Liking for Mathematics & $\begin{array}{l}26.95 \\
(6.85)\end{array}$ & $25.93(6.61))$ & $\begin{array}{l}26.52 \\
(6.67)\end{array}$ & 1,66 & 0.59 & 0.548 & 0.007 \\
\hline Self-Rating & $\begin{array}{l}20.34 \\
(5.81)\end{array}$ & $\begin{array}{l}21.65 \\
(4.27)\end{array}$ & $\begin{array}{l}21.09 \\
(4.91)\end{array}$ & 1,66 & 0.964 & 0.341 & 0.5 \\
\hline (Non)-Anxiety & $\begin{array}{l}16.53 \\
(7.4)\end{array}$ & $\begin{array}{l}22.85 \\
5.96\end{array}$ & $\begin{array}{l}19.27 \\
(7.03)\end{array}$ & 1,66 & 2.95 & 0.005 & 0.64 \\
\hline $\begin{array}{l}\text { (Non)-Unhappiness } \\
\text { at Failure }\end{array}$ & $\begin{array}{l}19.5 \\
(6.63)\end{array}$ & $\begin{array}{l}25.47 \\
(5.27)\end{array}$ & $\begin{array}{l}21.18 \\
(6.16)\end{array}$ & 1,66 & 3.07 & 0.003 & 0.836 \\
\hline
\end{tabular}


first year of primary school. It is interesting that such young children show similar results to the somewhat older primary school children in previous studies.

\subsection{Relations between attitudes and performance}

The second prediction that there would be relatively little relationship between attitudes and performance was partially but not completely confirmed, while the third prediction that there would be a specific relationship between self-rating and performance in the Chinese group was supported to some extent, but much less than in the English group, which had not been expected to show such a relationship at this age. There was more association between attitudes on performance than is sometimes found with young children (e.g. Dowker et al., 2012), with attitudes accounting for approximately $26 \%$ of the variance in arithmetical performance in the group as a whole. But Self-rating was the only individual attitude variable that correlated significantly with performance, and it remained significant as an independent predictor in a multiple regression after controlling for other variables.

It is interesting that attitudes were far more strongly related to performance in the English group specifically than had been predicted for children of such a young age. Self-rating was a strong independent predictor of performance in the English group, and (Non)-unhappiness at poor performance was also a predictor. Such relationships have in previous studies only been found in rather older primary school children (Dowker et al., 2012; Ho et al., 2000; Krinzinger et al., 2007; Sorvo et al., 2017). It may be that the increasing emphasis on early assessment in UK primary schools (e.g. the Early Years Foundation Stage Profile) is making children more aware of, and perhaps more concerned about, their performance at an early stage.

The findings of the present study are in line with findings that in somewhat older primary school children, self-rating is a particularly strong correlate of mathematics performance: stronger than, for example, mathematics anxiety (Dowker et al., 2012; Krinzinger et al., 2007; Wood et al., 2012). There are several possible reasons for this relationship. It may be that the causal direction is from performance to self-rating: i.e. children are relatively accurate in their self-ratings, and are aware of how well or badly they are performing in class. It may also be that high self-esteem in mathematics contributes to children's willingness to practice the subject, and to persist in the face of difficulties. Longitudinal studies suggest that there are relationships in both directions (e.g. Aunola, Leskinen, \& Nurmi, 2006). It is also found that teachers' ratings of children's mathematical ability influence both children's later self-ratings and actual performance (Upadyaya \& Eccles, 2015). The same is true for parent ratings, though this relationship appears more noticeable in the later primary years than earlier (Herbert \& Stipek, 2005).

It is interesting that unhappiness at failure - but not anxiety itself - was found to be a predictor of performance. This is in contrast with the studies that show a strong relationship between anxiety and performance in older children and adults. It is also in contrast with findings that indicate relatively little relationship between attitudes and performance in very young children, though not many studies have looked directly at unhappiness at failure. The findings could suggest that in the earliest stages of development, response to failure itself has a stronger influence on performance than response to anticipation of failure. Perhaps excessive distress at failure reduces the ability to learn from mistakes and thus to improve. The direction of causation could also be in the other direction: unhappiness at failure may be greater in those who have experienced more failures. 
Within-group analyses showed that, contrary to the fourth prediction, attitudes were more predictive of performance in the English than the Chinese group. Both self-rating and (non)unhappiness at failure predicted performance in the English group. Only self-rating correlated with arithmetical performance in the Chinese group, and it did not remain as a significant predictor after controlling for other variables in a multiple regression (though there was still a trend toward significance). Indeed attitude variables accounted for very little - only about $2 \%$ - of the variance in arithmetical performance in the Chinese group. This did not reflect any lack of variance in the attitude variables in that group, nor any worrying degree of collinearity of the variables. We may conclude that, at least in this particular Chinese group at this young age, self-reported attitudes had relatively little relationship to performance.

\subsection{Comparisons between English and Chinese children}

In accordance with the fifth prediction, the Chinese pupils performed much better than English pupils on the arithmetic test, despite the fact that the English pupils also obtained aboveaverage scores. This may be in part because they were somewhat older; but their standard scores also appeared to be much higher. This supports many findings that show better performance by Chinese pupils than those in Western countries (Leung, Graf, \& Lopez-Real, 2006; Mark \& Dowker, 2015; Mullis et al., 2016a; Mullis, Martin, Foy, \& Hooper, 2016b).

The sixth, seventh, and eighth predictions, which suggested that Chinese children would show more negative attitudes to mathematics than English children, were not supported. The groups did not differ on most of the attitude variables, and the Chinese pupils indeed gave much higher self-ratings of their own mathematical ability than did the English children. This finding is consistent with the fact that the Chinese children actually did perform better than the English children. However, it was not consistent with the earlier findings that suggest that Chinese children and others from Pacific Rim countries are actually more anxious and less confident than many from Western countries, perhaps due to the amount of academic pressure placed on them (Askew, Hodgen, Hossain, \& Bretscher, 2010; Dulaney et al., 2017). It may be that the higher Chinese self-ratings found in the present study are a function of the children's younger age in comparison with those of the previous studies. It may be that they become more anxious and less confident as a result of increased academic pressure and testing over the years. Further research should study Chinese children of different ages, starting with first-grade children, to investigate whether there are indeed changes with age in Chinese children's attitudes, and whether they coincide with any changes in teaching methods as children grow older.

\subsection{Relations between the different attitudes}

Examinations of correlations between variables in the group overall and in the separate national groups showed that Self-Rating was correlated with (Non)-Anxiety and with Liking for mathematics. Liking for mathematics was correlated with (Non)Unhappiness at failure, but not with (Non)-Anxiety. Surprisingly, (Non)-Anxiety was not significantly correlated with (Non) Unhappiness at failure in the group as a whole, or among the English children specifically though there was a significant correlation between the two variables in the Chinese group on its own. The importance of Selfrating in predicting both performance and other attitudes is consistent with the 
findings of Dowker et al. (2012) for somewhat older primary school children, and with Jameson's (2014) finding that mathematical self-concept was the strongest negative predictor of anxiety in second-grade pupils. It had not, however, been predicted for such young children.

It would be of interest to compare children of different ages, or ideally to follow-up the same children longitudinally, to see whether the relationships between different attitudes change with age. Ganley and McGraw (2016) found that the relationships between different attitudes increased with age. For example, they found that interest in mathematics, but not mathematical self-confidence, predicted mathematics anxiety in a sample of American first-grade children, while both, together with regarding mathematics as important, predicted mathematics anxiety in third grade pupils. In the present study, liking for mathematics did not show a significant relationship to anxiety, while self-rating did.

\subsection{Gender, attitudes, and performance}

Unfortunately, gender information was only available for individual children in the English group, so the gender analyses could only be carried out for that group. Within that group, the ninth prediction that there would be no gender differences in performance was confirmed. The tenth, that boys would show higher self-rating than girls, was not supported. There were gender differences in other attitudes, but not in the direction that might have been expected on the basis of studies of older children. Although studies of older children, adolescents, and adults usually show higher levels of mathematics anxiety in females than males (Devine et al., 2012), most studies had not shown any gender differences in anxiety in very young children (Dowker et al., 2012; Erturan \& Jansen, 2015; Harari et al., 2013; Wu et al., 2014). However, the present study showed some gender differences in the English sample, but in the unexpected direction of greater anxiety and unhappiness over failure in boys. This result would need replication in similar age-groups, before any strong interpretation could be made. If it is replicated, it might reflect the generally more negative attitudes that boys have to schoolwork in primary school, which have been suggested to be possibly related to their lower verbal and social maturity at school entrance in a school system where children begin formal instruction very early (e.g., Lever-Chain, 2002). It would also be desirable to investigate gender differences in other national cultural groups, and to investigate the possibility of interactions between culture and gender regarding attitudes, performance, and relationships between them.

\subsection{Limitations of the study and implications for further research}

Some caution is needed in drawing strong conclusions, as the sample sizes were relatively small, and in particular the Chinese children were only from one part-Hong Kong - of a huge country. Future studies should include larger samples from a wider variety of regions and, if possible, countries. It is also desirable to incorporate more study of the contexts in which the children are learning, which are likely to vary in multiple ways, so that cultural or national differences can rarely be reduced to a single factor. Moreover, the English participants may have been somewhat unrepresentative, in that they had above-average British Abilities Scales standard scores. In this respect, 
however, they did not differ greatly from those some other studies of children, e.g. the study by Dowker et al. (2012); or from most studies of adults, which commonly use university students as participants. One important limitation to be noted is that the study was cross-sectional rather than longitudinal. It would be desirable to carry out more longitudinal studies starting from an early stage of schooling.

It would also be of interest to study other attitudes to mathematics, e.g. children's views of how interesting and engaging their school mathematics lessons are. The TIMSS studies have shown fourth-graders' attitudes to this issue to be extremely positive in a wide range of countries: more positive than their liking for mathematics as such (Mullis et al., 2016a, 2016b). Future studies could also assess children's self-efficacy; how easy or difficult they consider mathematics to be; and how useful they consider it to be. It would also be desirable to look at both performance and attitudes with regard to a wider range of mathematical tasks. Both the questionnaire and the standardized test used in the study focused mainly on computation; and one should investigate whether similar results would be obtained for other aspects including applications of arithmetic, number representation (e.g. on number lines), measurement, and shape and space. Finally, this study used questionnaire measures and focused on cognitive aspects of attitudes to mathematics. Future studies could include measures of emotional aspects of mathematics anxiety, which earlier studies suggest might be more closely related to performance even in young children than the cognitive aspects are, and could incorporate direct physiological measures of emotions related to mathematics, e.g. heart rate and skin conductance.

\subsection{Implications for education}

The study suggests that attitudes to mathematics are associated with arithmetical performance even in children in the first year at school, with self-rating and unhappiness at failure being much more important than anxiety, or for that matter liking for mathematics, in predicting mathematical performance. Though it is not at present possible to determine direction of causation, results suggest that it may be desirable to focus in these early years on reducing distress at failure, and on preserving confidence in ability to solve mathematical problems.

\section{APPENDIX 1: Questionnaire items from the Mathematics Attitude and Anxiety Questionnaire (Thomas \& Dowker, 2000)}

\section{PRACTICE ITEMS}

Show me on this how good you think you are at schoolwork.

Show me on this how much you like or hate schoolwork.

Show me on this how happy or unhappy you would feel if you did badly at something in schoolwork.

Show me on this how worried or relaxed you would feel if you couldn't do something in schoolwork.

Show me on this how good you think you are at written work.

Show me on this how much you like or hate written work. 
Show me on this how happy or unhappy you would feel if you did badly at something in written work.

Show me on this how worried or relaxed you would feel if you couldn't do something in written work.

\section{MAIN ITEMS}

Supposing you are having a maths lesson:

Show me on this how good you think you are at maths in general.

Show me on this how much you like or hate maths in general.

Show me on this how happy or unhappy you would feel if you did badly at something in maths.

Show me on this how worried or relaxed you would feel if you couldn't do something in maths.

Show me on this how good you think you are at written sums.

Show me on this how much you like or hate written sums.

Show me on this how happy or unhappy you would feel if you did badly at a written sum.

Show me on this how worried or relaxed you would feel if you couldn't do a written sum.

(The same questions were asked about mental sums; easy maths; difficult maths; taking tests in maths; and listening to the teacher talking about maths).

Show me on this how good you think you are at easy maths.

Show me on this how much you like or hate easy maths.

Show me on this how happy or unhappy you would feel if you did badly at something in easy maths.

Show me on this how worried or relaxed you would feel if you couldn't do something in easy maths.

Show me on this how good you think you are at difficult maths.

Show me on this how much you like or hate difficult maths.

Show me on this how happy or unhappy you would feel if you did badly at something in difficult maths.

Show me on this how worried or relaxed you would feel if you couldn't do something in difficult maths.

Show me on this how good you think you are at maths tests.

Show me on this how much you like or hate maths tests.

Show me on this how happy or unhappy you would feel if you did badly at a maths test.

Show me on this how worried or relaxed you would feel if you couldn't do a maths test.

Show me on this how good you think you are at understanding the teacher when she talks about maths.

Show me on this how much you like or hate trying to understand what the teacher says about maths.

Show me on this how happy or unhappy you would feel if you did badly at understanding the teacher when she talks about maths.

Show me on this how worried or relaxed you would feel if you couldn't understand the teacher when she talks about maths. 


\section{APPENDIX 2}

\section{$\underline{\text { Rating Scales }}$}
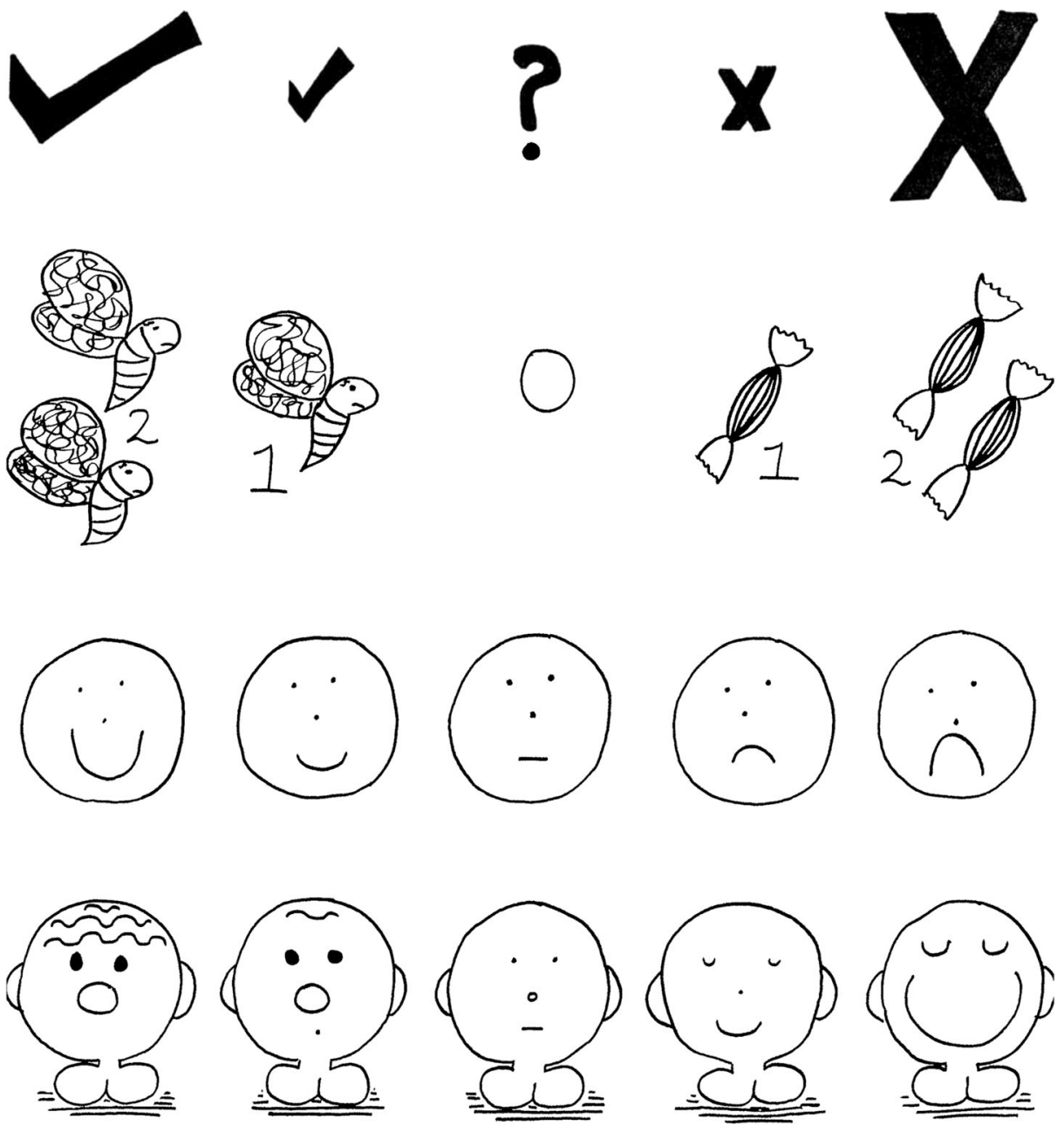

Fig. 1 Pictorial rating scale from the Mathematics Attitude and Anxiety Questionnaire (Thomas \& Dowker, 2000) (see attached) 
Open Access This article is distributed under the terms of the Creative Commons Attribution 4.0 International License (http://creativecommons.org/licenses/by/4.0/), which permits unrestricted use, distribution, and reproduction in any medium, provided you give appropriate credit to the original author(s) and the source, provide a link to the Creative Commons license, and indicate if changes were made.

Publisher's note Springer Nature remains neutral with regard to jurisdictional claims in published maps and institutional affiliations.

\section{References}

Abed, A. S., \& Alkhateeb, H. M. (2000). Mathematics anxiety among eighth-grade students of the United Arab Emirates. Psychological Reports, 86, 835-847. https://doi.org/10.2466/PR0.89.5.65-66

Adelson, J., \& McCoach, D. B. (2011). Development and psychometric properties of the Math and Me survey: Measuring third through sixth graders' enjoyment of mathematics. Measurement and Evaluation in Counseling and Development, 44, 225-247. https://doi.org/10.1177/0748175611418522

Ashcraft, M. H. (2002). Math anxiety: Personal, educational, and cognitive consequences. Current Directions in Psychological Science., 11, 181-185. https://doi.org/10.1111/1467-8721.00196

Askew, M., Hodgen, J., Hossain, S., \& Bretscher, N. (2010). Values and variables: Mathematics education in high-performing countries. London: Nuffield Foundation.

Aunola, K., Leskinen, E., \& Nurmi, J. E. (2006). Developmental dynamics between mathematical performance, task motivation, and teacher's goals during the transition to primary school. British Journal of Educational Psychology, 76, 21-40. https://doi.org/10.1348/000709905X51608

Blatchford, P. (1996). Pupils' views on school work and school from 7 to 16 years. Research Papers in Education, 11 ,263-288. https://doi.org/10.1080/0267152960110305

Breckler, S. J. (1984). Empirical validation of affect, behavior, and cognition as distinct components of attitude. Journal of Personality and Social Psychology, 47(6), 1191-1205. https://doi.org/10.1037/00223514.47.6.1191

Carey, E., Hill, F., Devine, A., \& Szucs, D. (2016). The chicken or the egg? The direction of the relationship between mathematics anxiety and mathematics performance. Frontiers in Psychology, 6, 1987. https://oi. org/10.3389/fpsyg.2015.01987

Cargnelutti, E., Tomasetto, C., \& Passolunghi, M. C. (2017). The interplay between affective and cognitive factors in shaping early proficiency in mathematics. Trends in Neuroscience and Education, 8-9, 28-36. https://doi.org/10.1016/j.tine.2017.10.002

Ching, B. H. H. (2017). Mathematics anxiety and working memory: Longitudinal associations with mathematical performance in Chinese children. Contemporary Educational Psychology, 51, 99-113. https://doi. org/10.1016/j.cedpsych.2017.06.006

Devine, A., Fawcett, K., Szucs, D., \& Dowker, A. (2012). Gender differences in mathematics anxiety and the relation to mathematics performance while controlling for test anxiety. Behavioral and Brain Functions., 8 , 33. https://doi.org/10.1186/1744-9081-8-33

Dowker, A., Bennett, K., \& Smith, L. (2012). Attitudes to mathematics in primary school children. Child Development Research, 2012, 124939-124938. https://doi.org/10.1155/2012/124939

Dowker, A., Sarkar, A., \& Looi, C. Y. (2016). Mathematics anxiety: What have we learned in 60 years? Frontiers in Psychology, 7(508). https://doi.org/10.3389/fpsyg.2016.00508

Else-Quest, N., Hyde, J. S., \& Linn, M. (2010). Cross-national patterns of gender differences in mathematics: A meta-analysis. Psychological Bulletin, 136, 103-127. https://doi.org/10.1037/a0018053

Erturan, S., \& Jansen, B. (2015). An investigation of boys' and girls' emotional experience of math, their math performance, and the relation between these variables. European Journal of Psychology of Education, 30, 421-435. https://doi.org/10.1007/s10212-015-0248-7

Eysenck, M. W., \& Calvo. M. G. (1992). Anxiety and performance: The processing efficiency theory. Cognition and Emotion. 6, 409-434. https://doi.org/10.1080/02699939208409696

Ganley, C. M., \& Lubienski, S. T. (2016). Mathematics confidence, interest, and performance: Examining gender patterns and reciprocal relations. Learning and Individual Differences, 47, 182-193. https://doi.org/10.1016 /j.lindif.2016.01.002

Ganley, C. M., \& McGraw, A. L. (2016). The development and validation of a revised version of the math anxiety scale for young children. Frontiers in Psychology, 7(1181). https://doi.org/10.3389 /fpsyg.2016.01181

Gierl, M. J., \& Bisanz, J. (1995). Anxieties and attitudes related to mathematics in grades 3 and 6. Journal of Experimental Education, 63, 139-158. https://doi.org/10.1080/00220973.1995.9943818 
Gottfried, A. E., Marcoulides, G. A., Gottfried, A. W., Oliver, P. H., \& Guerin, G. W. (2007). Multivariate latent change modelling of developmental decline in academic intrinsic math motivation and achievement: Childhood through adolescence. International Journal of Behavioral Development, 31, 317-327. https://doi.org/10.1177/0165025407077752

Harari, R. R., Vukovic, R. K., \& Bailey, S. P. (2013). Mathematics anxiety in young children: An exploratory study. Journal of Experimental Education, 81, 538-555. https://doi.org/10.1155/2012/98267

Hembree, R. (1990). The nature, effects, and relief of mathematics anxiety. Journal for Research in Mathematics Education, 21, 33-46. https://doi.org/10.2307/749455

Herbert, J., \& Stipek, D. (2005). The emergence of gender differences in children's performance of their academic competence. Applied Developmental Psychology, 26, 276-295. https://doi.org/10.1016/j. appdev.2005.02.007

Ho, H. Z., Senturk, D., Lam, A. G., Zimmer, J. M. ., Hong, S., Okamoto, Y., ... Wang, C. P. (2000). The affective and cognitive dimensions of math anxiety: A cross-national study. Journal for Research in Mathematics Education, 31, 362-379. https://doi.org/10.2307/749811

House, J. D. (2006). Mathematics beliefs and achievement of elementary school students in Japan and the United States: Results from the third international mathematics and science study. The Journal of Genetic Psychology, 167, 31-45. https://doi.org/10.3200/GNTP.167.1.31-45

Jameson, M. M. (2013). The development and validation of the Children's Anxiety in Math Scale. Journal of Psychoeducational Assessment, 31, 391-395. https://doi.org/10.1177/0734282912470131

Jameson, M. M. (2014). Contextual factors related to math anxiety in second-grade children. Journal of Experimental Education, 82, 518-536. https://doi.org/10.1080/00220973.2013.813367

Jansen, B. R. J., Louwerse, J., Straatemeier, M., Van der Ven, S. H. G., Klinkenberg, S., \& Van der Maas, H. L. J. (2013). The influence of experiencing success in math on math anxiety, perceived math competence, and math performance. Learning and Individual Differences, 24, 190-197. https://doi.org/10.1016/j. lindif.2012.12.014

Krinzinger, H., Kaufmann, L., \& Willmes, L. (2009). Math anxiety and math ability in early primary school years. Journal of Psychoeducational Assessment, 27, 206-225. https://doi.org/10.1177/0734282908330583

Krinzinger, H., Kaufmann, L., Dowker, A., Thomas, G., Graf, M., Nuerk, H. C., \& Willmes, K. (2007). German version of the math anxiety questionnaire (FRA) for 6- to 9year-old children. [German]. Zeitschrift fur Kinder und Jugendpsychiatrie und Psychotherapie, 35, 341-351.

Kyttala, M., \& Bjorn, P. M. (2010). Prior mathematics achievement, cognitive appraisals and anxiety as predictors of Finnish students' later mathematics performance and career orientation. Educational Psychology, 30, 432-448. https://doi.org/10.1080/01443411003724491

Lever-Chain, J. (2002). The impact of age of entry to school on boys' attitudes and skills during Key Stage 1. University of London Institute of Education: Ph.D. Thesis.

Leung, F. K. S., Graf, K. D., \& Lopez-Real, F. J. (Eds.). (2006). Mathematics education in different cultural traditions: A comparative study of East Asia and the West. The 13th ICMI study. Dordrecht: Springer. https://doi.org/10.1007/0-387-29723-5

Ma, X., \& Kishor, N. (1997). Assessing the relationship between attitude toward mathematics and achievement in mathematics: A meta-analysis. Journal for Research in Mathematics Education, 28, 26-47. https://doi. org/10.2307/749662

Ma, X., \& Xu, J. (2004). Determining the causal order between attitude toward mathematics and achievement in mathematics. American Journal of Education, 100, 256-281. https://doi.org/10.1086/383074

Maloney, E. A., \& Beilock, S. (2012). Math anxiety: Who has it, why it develops, and how to guard against it. Trends in Cognitive Sciences, 16, 404-406. https://doi.org/10.1016/j.tics.2012.06.008

Maloney, E. A., Ansari, D., \& Fugelsang, J. A. (2011). The effect of mathematics anxiety on the processing of numerical magnitude. Quarterly Journal of Experimental Psychology, 64, 10-16. https://doi.org/10.1080 $/ 17470218.2010 .533278$

Mark, W., \& Dowker, A. (2015). Linguistic influence on mathematical development is specific rather than pervasive: Revisiting the Chinese Number Advantage in Chinese and English children. Frontiers in Psychology, 6, 203. https://doi.org/10.3389/fpsyg.2015.00203

Markovits, Z., \& Forgasz, H. (2017). "Mathematics is like a lion": Elementary students' beliefs about mathematics. Educational Studies in Mathematics, 96, 49-64. https://doi.org/10.1007/s10649-017-9759-2

Mullis, I. V. S., Martin, M. O., \& Loveless, T. (2016a): 20 Years of TIMSS: International Trends in Mathematics and Science Achievement, Curriculum, and Instruction. Boston, USA: International TIMSS and PIRLS Study Centre.

Mullis, I. V. S., Martin, M. O., Foy, P., \& Hooper, M. (2016b). TIMSS 2015 international results in mathematics. Boston, USA: International TIMSS and PIRLS Study Centre.

Petronzi, D. (2016). The development of the Numeracy Apprehension Scale for children aged 4-7 years: Qualitative exploration of associated factors and quantitative testing. University of Derby: Ph.D. Thesis. 
Pinxten, M., Marsh, H., DeFraine, B., Van den Noortgate, W., \& Van Damme, J. (2014). Enjoying mathematics or feeling competent in mathematics? Reciprocal effects on mathematics achievement and perceived math effort expenditure. British Journal of Educational Psychology, 84, 152-174. https://doi.org/10.1111 /bjep.12028

Ramirez, G. E. A., Gunderson, E. A., Levine, S. C., \& Beilock, S. L. (2013). Math anxiety, working memory and math achievement in early elementary school. Journal of Cognition and Development, 14, 187-202. https://doi.org/10.1080/15248372.2012.664593

Richardson, F. G., \& Suinn, R. M. (1972). The mathematics anxiety rating scale: Psychometric data. Journal of Counseling Psychology, 19, 551-554. https://doi.org/10.1037/h0033456

Skaalvik, S., \& Skaalvik, E. M. (2004). Gender differences in math and verbal self-concept, performance expectations and motivation. Sex Roles, 50, 241-252. https://doi.org/10.1023/B:SERS.0000015555.40976. e6

Sorvo, R., Koponen, T., Viholainen, H., Aro, T., Raikkönen, E., Peura, P., ... Aro, M. (2017). Math anxiety and its relationship with basic arithmetic skills among primary school children. British Journal of Educational Psychology, 87, 309-327. https://doi.org/10.1111/bjep.12151

Stevenson, H. W., Hofer, B. K., \& Randel, B. (2000). Mathematics achievement and attitudes about mathematics in China and the West. Journal of Psychology in Chinese Societies, 1, 1-16.

Thomas, G. \& Dowker, A. (2000). Mathematics anxiety and related factors in young children. Paper presented at British Psychological Society Developmental Section Conference, Bristol, September 15th, 2000.

Upadyaya, K., \& Eccles, J. (2014). Do teachers' belief predict children's interest in math from kindergarten to sixth grade? Merrill-Palmer Quarterly, 60, 403-430. https://doi.org/10.13110/merrpalmquar1982.60.4.0403

Upadyaya, K., \& Eccles, J. (2015). Do teachers' perceptions of children's math and reading related ability and effort predict children's self-concept of ability in math and reading? Educational Psychology, 35, 110-127. https://doi.org/10.1080/01443410.2014.915927

Van der Beek, J., Van der Ven, S., Kroesbergen, E., \& Leseman, P. (2017). Self-concept mediates the relation between achievement and emotions in mathematics. British Journal of Educational Psychology, 87, 478495. https://doi.org/10.1111/bjep. 12160

Vukovic, R. K., Kieffer, M. J., Bailey, S. P., \& Harari, R. R. (2013). Mathematics anxiety in young children: Concurrent and longitudinal associations with mathematical performance. Contemporary Educational Psychology, 38, 1-10. https://doi.org/10.1016/j.cedpsych.2012.09.001

Wigfield, A., \& Meece, J. L. (1988). Math anxiety in elementary and secondary school students. Journal of Educational Psychology, 80, 210-216. https://doi.org/10.1037/0022-0663.80.2.210

Wood, G., Pinheiro-Chagas, P., Júlio-Costa, A., Micheli, L. R., Krinzinger, H., Kaufmann, L., et al. (2012). Math anxiety questionnaire: Similar latent structure in Brazilian and German school children. Child Development Research, 2012(610192). https://doi.org/10.1155/2012/610192

Wu, S. S., Barth, M., Amin, H., Malcarne, V., \& Menon, V. (2012). Math anxiety in second and third graders and its relation to mathematics achievement. Frontiers in Psychology, 3, 1-11. https://doi.org/10.3389 /fpsyg.2012.00162

Wu, S. S., Willcutt, E. G., Escovar, E., \& Menon, V. (2014). Mathematics achievement and anxiety and their relation to internalizing and externalizing behaviors. Journal of Learning Disabilities, 47, 503-514. https://oi.org/10.1177/0022219412473154

\section{Affiliations}

\section{Ann Dowker ${ }^{1} \cdot$ Olivia Cheriton $^{2} \cdot$ Rachel Horton ${ }^{3} \cdot$ Winifred Mark ${ }^{4}$}

1 Department of Experimental Psychology, Oxford University, 15 Parks Road, Oxford OX1 3PG, UK

2 Magdalen College, Oxford, UK

3 St Anne's College, Oxford, UK

4 Hong Kong University, Hong Kong, China 